\title{
Insulin-regulated aminopeptidase inhibitors do not alter glucose handling in normal and diabetic rats
}

\author{
Anthony L Albiston', Mauricio Cacador1, Puspha Sinnayah', Peta Burns ${ }^{2}$ and \\ Siew Yeen Chai
}

${ }^{1}$ College of Health and Biomedicine, Victoria University St Albans, Victoria, Australia

2Department of Physiology, Biomedicine Discovery Institute, Monash University, Clayton, Victoria, Australia
Correspondence should be addressed to S Y Chai Email siew.chai@monash.edu

\begin{abstract}
Insulin-regulated aminopeptidase (IRAP) co-localizes with the glucose transporter 4 (GLUT4) in GLUT4 storage vesicles (GSV) in insulin-responsive cells. In response to insulin, IRAP is the only transmembrane enzyme known to translocate together with GLUT4 to the plasma membrane in adipocytes and muscle cells. Although the intracellular region of IRAP is associated with GLUT4 vesicle trafficking, the role of the aminopeptidase activity in insulin-responsive cells has not been elucidated. The aim of this study was to investigate whether the inhibition of the aminopeptidase activity of IRAP facilitates glucose uptake in insulin-responsive cells. In both in vitro and in vivo studies, inhibition of IRAP aminopeptidase activity with the specific inhibitor, HFI-419, did not modulate glucose uptake. IRAP inhibition in the L6GLUT4myc cell line did not alter glucose uptake in both basal and insulin-stimulated state. In keeping with these results, HFI419 did not affect peripheral, whole-body glucose handling after an oral glucose challenge, neither in normal rats nor in the streptozotocin (STZ)-induced experimental rat model of diabetes mellitus (DM). Therefore, acute inhibition of IRAP aminopeptidase activity does not affect glucose homeostasis.
\end{abstract}

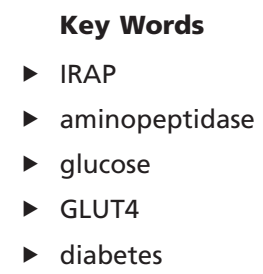

Journal of Molecular Endocrinology (2017) 58, 193-198

\section{Introduction}

Insulin-regulated aminopeptidase (IRAP) is a marker protein for specialized vesicles containing the insulinresponsive glucose transporter 4 (GLUT4) (Keller et al. 1995). IRAP is localized in distinct organelles within insulin-dependent cells, including sorting and recycling endosomes, the endosomal-trans-Golgi network (TGN) and GLUT4 storage vesicles (GSVs) (Bryant et al. 2002).

IRAP is a type II integral membrane protein of $160 \mathrm{kDa}$ and a member of the M1 aminopeptidase family (Keller et al. 1995). IRAP has two major functional domains: the carboxy terminal catalytic domain, containing the GAMEN motif (amino acids 428-432) and the $\operatorname{HEXXH}(\mathrm{X})_{18} \mathrm{E} \mathrm{Zn}^{2+}$-binding motif (amino acids 464-487) and a highly conserved intracellular amino terminal trafficking domain. In insulin-responsive cells, the intracellular domain is found to bind to a number of proteins, including AS160, and demonstrated to modulate insulin-dependent GSV tethering and trafficking (Ross et al. 1996), reviewed in Albiston and coworkers (Albiston et al. 2007).

In the basal state, IRAP occurs predominantly in intracellular vesicles where the catalytic site is intraluminal. Upon insulin stimulation, IRAP translocates to the plasma membrane with GLUT4, where the catalytic

Published by Bioscientifica Ltd 
site is exteriorized. The functional importance of the aminopeptidase activity in relation to glucose uptake in insulin-responsive cells has not been elucidated. We have previously demonstrated that two structurally distinct classes of IRAP inhibitors, the peptide-based angiotensin IV and LVV hemorphin-7 and the benzopyran-based HFI-419, all enhanced glucose uptake in hippocampal neurons depolarized with either potassium or cAMP (Albiston et al. 2008, Fernando et al. 2008). However, in the basal state, IRAP inhibitors did not alter glucose uptake in hippocampal neurons, nor were we able to demonstrate an insulin-stimulated glucose uptake (Albiston et al. 2008, Fernando et al. 2008). To delineate the potential role of the aminopeptidase activity of IRAP on insulin-dependent glucose uptake, we utilized the well-characterized insulin-responsive muscle cell line L6GLUT4myc. In this study, we investigated whether the IRAP inhibitor, HFI-419, modulated glucose uptake in either the basal or insulin-stimulated L6GLUT4myc cells. Consistent with other insulin-responsive cells, in L6 cells, IRAP is found predominantly in GLUT4 vesicles and translocates with GLUT4 to the plasma membrane after insulin stimulation (Urso et al. 1999, Li et al. 2016). In addition, we investigated the effect of this inhibitor on glucose clearance in vivo in normal and streptozotocin (STZ)-induced diabetes mellitus (DM) rats after an oral glucose challenge.

\section{Materials and methods}

\section{Materials}

1-Leucine-4-methyl-7-coumarinylamide

(Leu-MCA) (Sigma-Aldrich). IRAP inhibitor, HFI-419, was dissolved in dimethyl sulfoxide (DMSO, Calbiochem). For animal studies, HFI-419 was first dissolved in 100\% DMSO, and then diluted $1: 10$ in 30\% (2-hydroxypropyl)$\beta$-cyclodextrin (HPBCD; Sigma-Aldrich) to the final concentration. Streptozotocin was purchased from ICN Biomedicals Inc., Ohio. Actrapid insulin (100 IU/mL) was purchased from Novo Nordisk Pharmaceuticals Ltd. L6GLUT4myc cells were used between passages 14 and 16 and were a generous gift from Prof. A Klip (Patel et al. 2003).

\section{Animals}

Adult, male, Sprague-Dawley rats were purchased from the Animal Resource Centre (Western Australia) and housed on a 12-h light/darkness cycle with ad libitum access to standard rat chow and water. All intramuscular (IM) injections were administered via caudal thigh muscle and all intravenous (IV) injections were administered via tail vein. All animal experiments were approved by the Howard Florey Institute Animal Ethics Committee.

\section{Measurement of radiolabeled 2-deoxyglucose uptake}

L6GLUT4myc cells were maintained in Dulbecco Modified Eagles Medium (DMEM) and 10\% fetal bovine serum (FBS) and differentiated in DMEM and 2\% FBS as described previously (Patel et al. 2003). Cells were used between days 8 and 10 after addition of differentiation media. Glucose uptake assays were performed using the d-2deoxy-d-[2,6-3 H]glucose ( $\left.{ }^{3} \mathrm{H}-2 \mathrm{DG}\right)$ as described previously (Yamamoto et al. 2011). In brief, cells were incubated in FBS-free medium for $24 \mathrm{~h}$, and then incubated in KrebsRinger-HEPES (KRH) buffer for $30 \mathrm{~min}$ with human insulin (Sigma-Aldrich) (0, 25 and $100 \mathrm{nM})$ plus or minus HFI-419 IRAP inhibitor $\left(10^{-6} \mathrm{M}\right.$ and $\left.10^{-7} \mathrm{M}\right)$, followed by addition of $5 \mathrm{mM} 2 \mathrm{DG}$ and $0.5 \mu \mathrm{Ci} /$ well of radiolabeled $2 \mathrm{DG}$ and a further 10-min incubation. For each assay, two wells were prepared with the inclusion of cytochalasin B $(20 \mu \mathrm{M})$ to determine the nonspecific glucose uptake. For the 24-h incubations with HFI-419, the inhibitor was added just after the change to FBS-free serum media the day before the glucose uptake assay was performed.

\section{Western blot analysis}

Cell lysates $(30 \mu \mathrm{g})$ were prepared and resolved on SDSPAGE followed by Western blotting for IRAP as previously described (Fernando et al. 2007). Blots were stripped and re-probed using the rabbit anti-GLUT4 (Abcam).

\section{Kinetic analysis of IRAP inhibition}

Recombinant IRAP was prepared, and kinetic analysis was performed as previously described except that the fluorescent substrate 1-leucine-4-methyl-7coumarinylamide (Leu-MCA) was utilized (Lew et al. 2003a). Linear regression analysis of kinetic data expressed in double-reciprocal (Lineweaver-Burk) form resulted in $R$ values greater than 0.99 for each curve. Inhibitory constant $\left(K_{\mathrm{i}}\right)$ for HFI-419 was calculated from the relationship $\mathrm{IC}_{50}=K_{\mathrm{i}}(1+(S) / K \mathrm{~m})$, where $K \mathrm{~m}$ for LeuMCA (Sigma-Aldrich) was determined from the kinetic experiments to be $38.7 \mu \mathrm{M}$ (Ye et al. 2008). http://jme.endocrinology-journals.org DOI: 10.1530/JME-17-0033
() 2017 Society for Endocrinology Printed in Great Britain
Published by Bioscientifica Ltd 


\section{Glucose handling after an oral glucose challenge}

The effect of IRAP inhibitor HFI-419 on whole animal glucose handling was evaluated after an oral glucose tolerance test (OGTT) in male Sprague-Dawley rats. Twelve rats were fasted overnight (approximately 16h) prior to intravenous administration of IRAP inhibitor HFI-419 $(0.5 \mathrm{mM}$ at a volume of $0.2 \mathrm{~mL})$ or vehicle (10\% DMSO, 30\% HPBCD, $0.2 \mathrm{~mL})$. Ten minutes after IV treatment, all rats were administered an oral glucose load of $300 \mathrm{mg} / 100 \mathrm{~g}$ body weight $(10 \mathrm{~g} / 30 \mathrm{~mL})$ using a $13 \mathrm{~g}$ gavage tube. Blood samples were taken from the tail vein, and glucose concentration was determined using an AccuChek meter and Advantage II glucose test strips (Roche Diagnostics). Blood was sampled immediately prior to IV treatment (basal) and at 30, 60, 120 and 240 min after glucose load.

\section{Glucose handling in streptozotocin-induced diabetic rats}

To induce diabetes, 16 male Sprague-Dawley rats were fasted overnight (approximately $16 \mathrm{~h}$ ) prior to IV administration of $50 \mathrm{mg} / \mathrm{kg}$ streptozotocin (STZ) dissolved in $50 \mathrm{mM}$ sodium citrate buffer, $\mathrm{pH} 4.5$. One week after the STZ treatment, rats displaying diabetic symptoms of polyuria and hyperglycemia (elevated plasma levels of glucose of $\sim 20 \mathrm{mM}$ ) were randomly assigned to one of the following four treatment groups with 4 rats per group: (i) IM water $(0.01 \mathrm{~mL})+\mathrm{IV}$ vehicle $(10 \% \mathrm{DMSO}$, $30 \%$ HPBCD, $200 \mu \mathrm{L}$ ), (ii) IM insulin, $(1 \mathrm{IU}, 0.01 \mathrm{~mL})+\mathrm{IV}$ vehicle $(200 \mu \mathrm{L})$, (iii) IM water $(0.01 \mathrm{~mL})+\mathrm{IV} 5 \mathrm{mM}$ HFI419 dissolved in 10\% DMSO, 30\% HPBCD $(0.2 \mathrm{~mL})$ and (iv) IM insulin (1 IU, $0.01 \mathrm{~mL})+$ IV $5 \mathrm{mM}$ HFI-419 $(0.2 \mathrm{~mL})$. Blood samples were taken from the tail for determination of glucose concentration using an AccuChek meter and Advantage II glucose test strips. Blood was sampled at $0 \mathrm{~min}$ (prior to IM and IV treatments) and at 30, 60, 120 and $240 \mathrm{~min}$ after IV vehicle or drug treatment.

\section{Results}

L6 GLUT4myc cells were demonstrated to express IRAP by Western blot analysis in agreement with previous literature (Fig. 1A). Consistent with other insulin-responsive cells, IRAP is found in GLUT4 vesicles in L6 cells and translocates with GLUT4 to the plasma membrane after insulin stimulation (Urso et al. 1999, Li et al. 2016). Under basal conditions, a percentage reduced amount of IRAP is present at the plasma membrane via recycling endosomes (Urso et al. 1999, Li et al. 2016). L6GLUT4myc myotubes
A

IRAP

$165 \mathrm{Kda}$

L6

L6GLUT4

GLUT4

$46 \mathrm{Kda}$

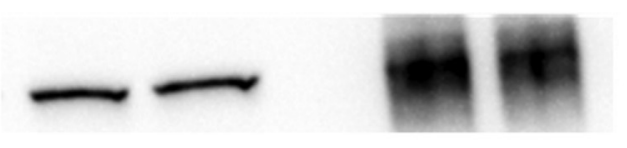

B

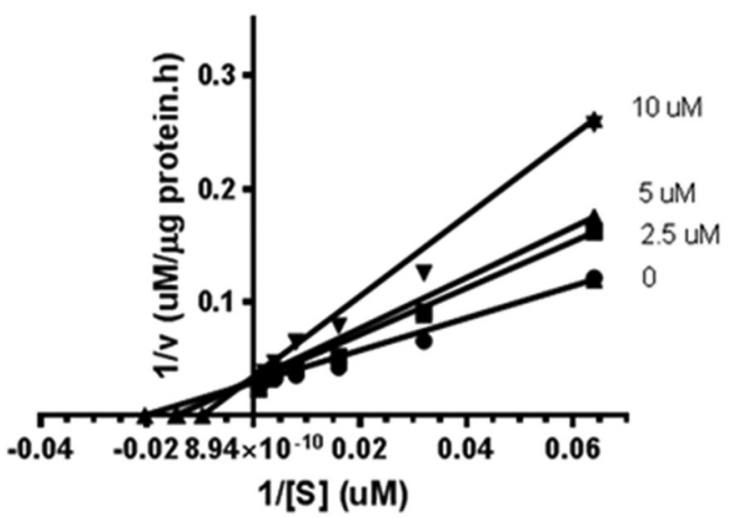

Figure 1

Expression of IRAP and GLUT4 in differentiated (myoblasts) L6 and L6GLUT4myc cells and inhibition of IRAP by HFI419. (A) Western blot analysis of IRAP and GLUT4. SDS protein samples were prepared from 6-well plates of each cell line 8-10 days after the addition of differentiation media. Thirty micrograms was loaded in each lane. (B) Kinetic analysis of IRAP inhibition. Shown are double-reciprocal (Lineweaver-Burk) plots of IRAP activity in the absence and presence of three concentrations of HFI419. Each point represents the mean \pm S.E.M. of three experiments performed in triplicate.

were stimulated with two different doses of insulin (low dose: $25 \mathrm{nM}$ and high dose: $100 \mathrm{nM}$ ) and tested with two doses of the HFI-419 IRAP inhibitor $\left(10^{-6} \mathrm{M}\right.$ or $\left.10^{-7} \mathrm{M}\right)$. HFI419 is a competitive inhibitor of IRAP as demonstrated in the Lineweaver-Burk plot (Fig. 1B) with a $\mathrm{Ki}$ of $0.48 \mu \mathrm{M}$ (Albiston et al. 2008). HFI-419 is highly specific for IRAP with $>1000$-fold lower or no affinity for related and unrelated enzymes (Albiston et al. 2008). In addition, a 'BioPrint Profile' screen by CEREP (France) against 106 known targets including GPCRs, ion channels, kinases and phosphatases demonstrated no cross-reactivity at micromolar concentrations. The IRAP inhibitor was administered for $30 \mathrm{~min}$, concurrent with the insulin stimulus (Fig. 2A) or incubated for $24 \mathrm{~h}$ prior to insulin stimulation (Fig. 2B). A significant increase in the glucose uptake by L6GLUT4myc cells was observed with insulin stimulation at both doses used (Fig. 2). However, the incubation of cells with HFI419 for either $30 \mathrm{~min}$ or $24 \mathrm{~h}$ did not alter glucose uptake in the basal state or under insulin-stimulated conditions (Fig. 2).

Published by Bioscientifica Ltd. 
A

$\mathrm{B}$

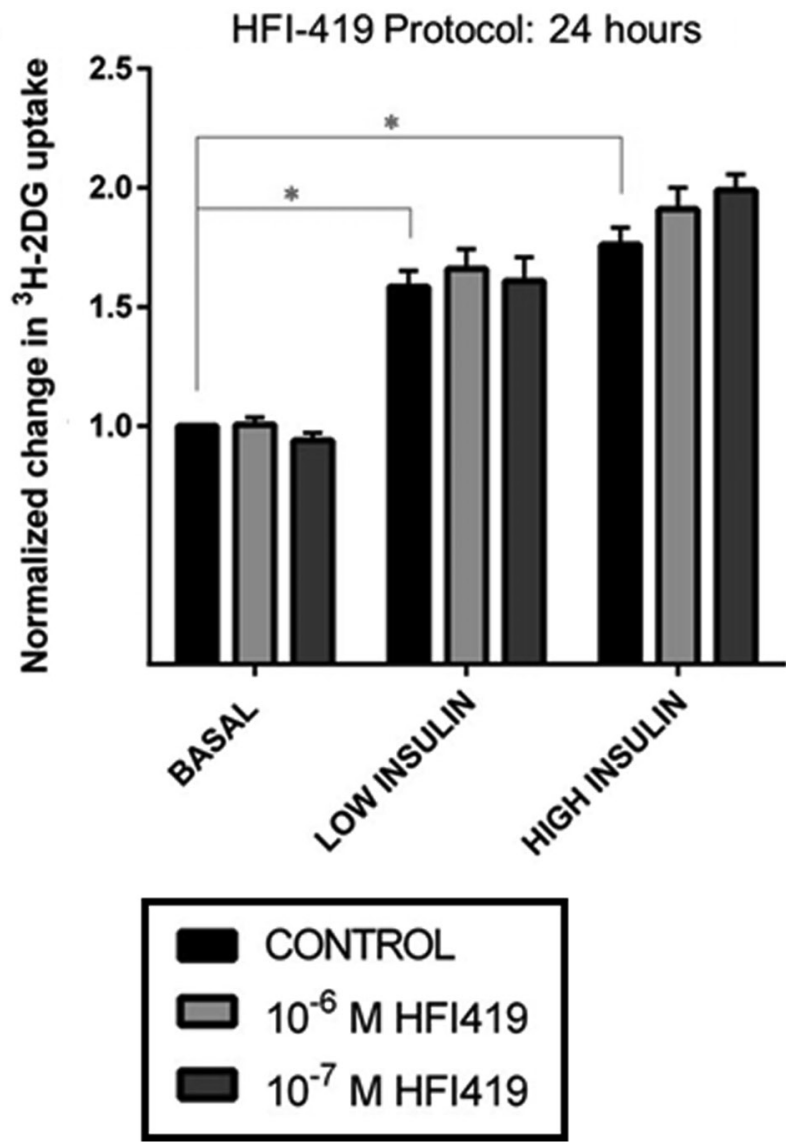

Figure 2

Inhibition of IRAP does not increase glucose uptake by L6GLUT4myc muscle cells. ${ }^{3} \mathrm{H}-2 \mathrm{DG}$ uptake in differentiated L6GLUT4myc muscle cells incubated for (A) 30 min or (B) $24 \mathrm{~h}$ with HFI-419 $\left(0,10^{-6} \mathrm{M}\right.$ and $\left.10^{-7} \mathrm{M}\right)$ plus or minus insulin $(0,25 \mathrm{nM}$ and $100 \mathrm{nM}$ insulin). Glucose uptake was

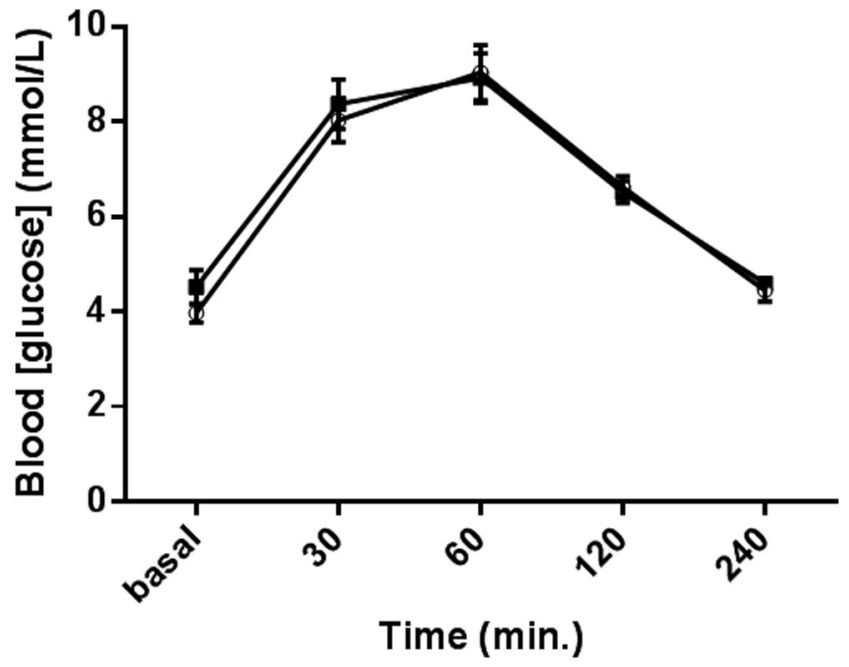

Figure 3

IRAP inhibition does not alter glucose handling in normal rats. Adult male Sprague-Dawley rats were fasted overnight and treated with (0) HFI-419 $(0.5 \mathrm{mM}, n=6)$ or (O) vehicle $(n=6)$ and an oral glucose tolerance test (OGTT) was performed as described in 'Materials and methods' section. No significant effect of HFI-419 treatment on OGTT results was observed. Data were analysed by repeated-measures 2-way ANOVA followed by Sidak's multiple comparisons test and is shown as mean \pm S.E.M.

The effect of IRAP inhibition on whole body glucose handling in normal rats was investigated. Treatment with HFI-419 did not alter the response to an oral glucose challenge. No difference was observed in peak blood glucose concentrations, recorded at $30 \mathrm{~min}$ after glucose load. The clearance of the glucose load, as measured by the return of blood glucose concentrations to basal levels over the following hours, was not different between HFI419 and vehicle-treated rats (Fig. 3).

In addition, the effect of IRAP inhibition on glucose handling in the STZ experimental rat model of diabetes was examined. Administration of STZ induced a diabetic state within one week with all rats displaying a basal blood glucose concentration of $>23 \mathrm{mmol} / \mathrm{L}$, which was not significantly different between the animals. STZ rats were then treated with HFI-419 with or without insulin. Treatment with insulin significantly decreased blood glucose concentrations below those of control (water)treated rats. However, treatment with IRAP inhibitor HFI419 did not alter the insulin response or basal glucose levels in STZ rats (Fig. 4).

calculated by normalizing the tritium content in stimulated state to that in basal state of the cells. Incubation with HFI-419 for $30 \mathrm{~min}$ or $24 \mathrm{~h}$ did not alter glucose uptake in either the basal or insulin stimulated conditions. Two-way ANOVA followed by a Tukey's post hoc test demonstrated that the cells responded significantly to insulin ((A) $n=4$, (B) $\left.n=7 ;{ }^{*} P \leq 0.05\right)$.

Published by Bioscientifica Ltd. 


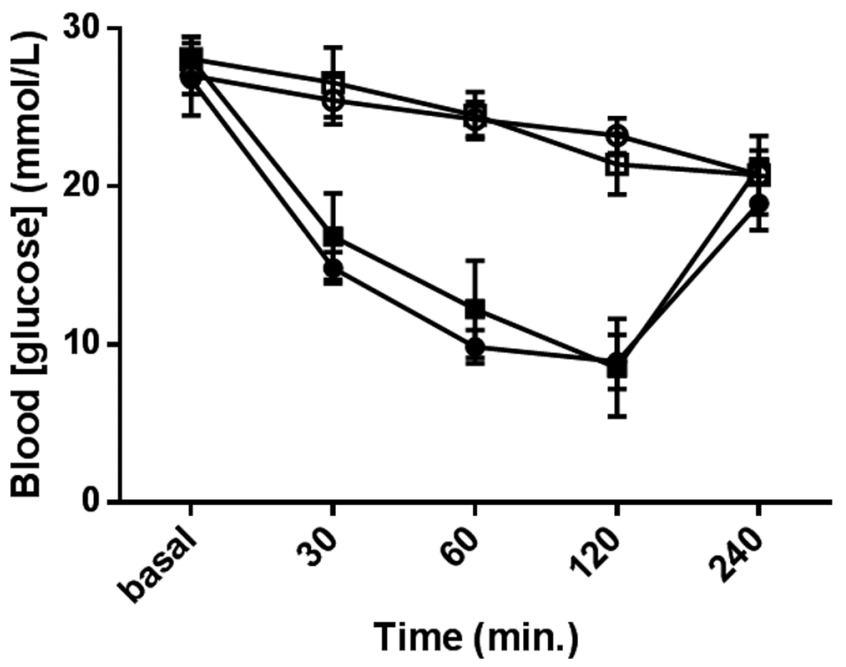

Figure 4

IRAP inhibition does not alter glucose levels in STZ-induced diabetic rats. Adult male Sprague-Dawley rats with STZ-induced diabetes were treated with HFI-419 (squares) $(0.5 \mathrm{mM}, n=6)$ or vehicle (circles) $(n=6)$ plus $1 \mathrm{IU}$ of insulin (filled symbols) or vehicle (open symbols). Data were analysed by 2-way ANOVA followed by Tukey's multiple comparisons test and is shown as mean \pm S.E.M. No significant effect of HFl-419 treatment on glucose levels in either the basal or insulin-stimulated states was observed.

\section{Discussion}

IRAP is capable of cleaving small bioactive peptides in vitro; these peptide substrates include vasopressin, oxytocin, lys-bradykinin, met-enkephalin, dynorphin A (1-8), neurokinin A, neuromedin B, somatostatin and CCK-8 (Herbst et al. 1997, Lew et al. 2003b). A soluble form of IRAP is produced by the placenta during pregnancy and released into the circulation. The circulating aminopeptidase plays a role in regulating vasopressin and oxytocin levels to present the onset of premature labor (Tsujimoto et al. 1992). In addition, IRAP was demonstrated to play a role in the immune system by trimming peptides for antigen cross-presentation via major histocompatibility class I (MHCI) molecules (Saveanu et al. 2005). However, a direct association between the cleavage of peptide substrates by IRAP and glucose uptake in insulin-responsive cells has not been established. Although insulin stimulation results in the trafficking of IRAP to the plasma membrane, the aminopeptidase does not cleave insulin and is therefore not part of a negative feedback mechanism (Lew et al. 2003b). This is in contrast to the negative feedback mechanism for IRAP that has previously been proposed for oxytocin, which was based on studies where oxytocin, an IRAP substrate, stimulated the translocation of IRAP to the plasma membrane in endothelial cells (Sano et al. 2005).

Utilizing the IRAP inhibitor, HFI-419, we were unable to demonstrate any changes in glucose uptake in both in vitro and in vivo systems. Using L6GLUT4myc cells, IRAP inhibition of both basal and insulin-stimulated cells did not alter glucose uptake; this was observed for both short (30-min) and 24-h incubations with HFI-419. In keeping with these results, HFI419 did not affect peripheral glucose handling in normal rats or in the STZ-induced diabetes mellitus rats during an oral glucose tolerance test. HFI419 had no effect on glucose handling in STZ rats with or without insulin treatment.

In contrast, we previously reported that HFI-419 potentiated glucose uptake in $\mathrm{K}^{+}$-evoked depolarized or cAMP-stimulated neurons (Fernando et al. 2008). The enhanced glucose uptake was demonstrated to be mediated by GLUT4 as the non-selective GLUT4 inhibitor, indinavir, blocked the effect. It was proposed that this effect may be due to increasing the half-life of IRAP and GLUT4 at the plasma membrane. This contrasting observation may be due to differences in GSVs in neurons compared to classic insulin-responsive cells such as muscle and adipocytes. In conclusion, our current study demonstrates that inhibition of IRAP catalytic activity does not modulate glucose uptake in insulin-responsive cells.

\section{Declaration of interest}

The authors declare that there is no conflict of interest that could be perceived as prejudicing the impartiality of the research reported.

\section{Funding}

This work was funded by a project grant from the National Health and Medical Research Council (NHMRC) of Australia and a VU internal CRGS project grant. S Y Chai was funded by an NHMRC Senior Research Fellowship.

\section{Author contribution statement}

A L Albiston wrote the manuscript, designed and interpreted the in vitro experiments and participated in the design and interpretation of the in vivo experiments. M Cacador conducted the in vitro glucose experiments. P Sinnyah participated in the design and interpretation of the glucose in vitro experiments. P Burns conducted the in vivo glucose handling experiments and $S Y$ Chai is the head of the laboratory who oversaw all aspects of the project from the design of the experiment to the interpretation of the results.
(C) 2017 Society for Endocrinology Printed in Great Britain
Published by Bioscientifica Ltd 


\section{References}

Albiston AL, Peck GR, Yeatman HR, Fernando R, Ye S \& Chai SY 2007 Therapeutic targeting of insulin-regulated aminopeptidase: heads and tails? Pharmacology and Therapeutics 116 417-427. (doi:10.1016/j. pharmthera.2007.07.006)

Albiston AL, Morton CJ, Ng HL, Pham V, Yeatman HR, Ye S, Fernando RN, De Bundel D, Ascher DB, Mendelsohn FA, et al. 2008 Identification and characterization of a new cognitive enhancer based on inhibition of insulin-regulated aminopeptidase. FASEB Journal 22 4209-4217. (doi:10.1096/fj.08-112227)

Bryant NJ, Govers R \& James DE 2002 Regulated transport of the glucose transporter GLUT4. Nature Reviews Molecular Cell Biology 3 267-277. (doi:10.1038/nrm782)

Fernando RN, Luff SE, Albiston AL \& Chai SY 2007 Sub-cellular localization of insulin-regulated membrane aminopeptidase, IRAP to vesicles in neurons. Journal of Neurochemistry 102 967-976. (doi:10.1111/j.1471-4159.2007.04659.x)

Fernando RN, Albiston AL \& Chai SY 2008 The insulin-regulated aminopeptidase IRAP is colocalised with GLUT4 in the mouse hippocampus; potential role in modulation of glucose uptake in neurones? European Journal of Neuroscience 28 588-598. (doi:10.1111/ j.1460-9568.2008.06347.x)

Herbst JJ, Ross SA, Scott HM, Bobin SA, Morris NJ, Lienhard GE \& Keller SR 1997 Insulin stimulates cell surface aminopeptidase activity toward vasopressin in adipocytes. American Journal of Physiology $\mathbf{2 7 2}$ E600-E606. (doi:10.1152/ajpendo.00440.200)

Keller SR, Scott HM, Mastick CC, Aebersold R \& Lienhard GE 1995 Cloning and characterization of a novel insulin-regulated membrane aminopeptidase from Glut4 vesicles. Journal of Biological Chemistry 270 23612-23618. (doi:10.1074/jbc.270.40.23612)

Lew RA, Mustafa T, Ye S, McDowall SG, Chai SY \& Albiston AL 2003a Angiotensin AT4 ligands are potent, competitive inhibitors of insulin regulated aminopeptidase (IRAP). Journal of Neurochemistry $\mathbf{8 6}$ 344-350. (doi:10.1046/j.1471-4159.2003.01852.x)

Lew RA, Mustafa T, Ye S, McDowall SG, Chai SY \& Albiston AL 2003b Angiotensin AT4 ligands are potent, competitive inhibitors of insulin regulated aminopeptidase (IRAP). Journal of Neurochemistry $\mathbf{8 6}$ 344-350. (doi:10.1046/j.1471-4159.2003.01852.x)
Li Y, Zheng L, Wang D, Zhang X, Li J, Ali S, Lu J, Zong H \& Xu X 2016 Staurosporine as an agonist for induction of GLUT4 translocation, identified by a $\mathrm{pH}$-sensitive fluorescent IRAP-mOrange2 probe. Biochemical and Biophysical Research Communications 480 534-538. (doi:10.1016/j.bbrc.2016.10.056)

Patel N, Rudich A, Khayat ZA, Garg R \& Klip A 2003 Intracellular segregation of phosphatidylinositol-3,4,5-trisphosphate by insulindependent actin remodeling in L6 skeletal muscle cells. Molecular and Cellular Biology 23 4611-4626. (doi:10.1128/МСB.23.13.4611-4626.2003)

Ross SA, Scott HM, Morris NJ, Leung WY, Mao F, Lienhard GE \& Keller SR 1996 Characterization of the insulin-regulated membrane aminopeptidase in 3T3-L1 adipocytes. Journal of Biological Chemistry 271 3328-3332. (doi:10.1074/jbc.271.6.3328)

Sano M, Itakura A, Ito M, Takeuchi M, Okada M, Kotani T, Mizutani S \& Kikkawa F 2005 Placental leucine aminopeptidase might regulate the effects of oxytocin with resolution in endothelial cells. Medical Science Monitor 11 BR195-BR199.

Saveanu L, Carroll O, Lindo V, Del Val M, Lopez D, Lepelletier Y, Greer F, Schomburg L, Fruci D, Niedermann G, et al. 2005 Concerted peptide trimming by human ERAP1 and ERAP2 aminopeptidase complexes in the endoplasmic reticulum. Nature Immunology 6 689-697. (doi:10.1038/ni1208)

Tsujimoto M, Mizutani S, Adachi H, Kimura M, Nakazato H \& Tomoda Y 1992 Identification of human placental leucine aminopeptidase as oxytocinase. Archives of Biochemistry and Biophysics 292 388-392. (doi:10.1016/0003-9861(92)90007-J)

Urso B, Cope DL, Kalloo-Hosein HE, Hayward AC, Whitehead JP, O'Rahilly S \& Siddle K 1999 Differences in signaling properties of the cytoplasmic domains of the insulin receptor and insulin-like growth factor receptor in 3T3-L1 adipocytes. Journal of Biological Chemistry 274 30864-30873. (doi:10.1074/jbc.274.43.30864)

Yamamoto N, Ueda M, Sato T, Kawasaki K, Sawada K, Kawabata K \& Ashida H 2011 Measurement of glucose uptake in cultured cells. Current Protocols in Pharmacology Chapter 12 Unit 12.14.11-22. (doi:10.1002/0471141755.ph1214s55)

Ye S, Chai SY, Lew RA, Ascher DB, Morton CJ, Parker MW \& Albiston AL 2008 Identification of modulating residues defining the catalytic cleft of insulin-regulated aminopeptidase. Biochemistry and Cell Biology 86 251-261. (doi:10.1139/O08-037)

Received in final form 16 March 2017

Accepted 29 March 2017

Accepted Preprint published online 29 March 2017 http://jme.endocrinology-journals.org DOI: 10.1530/JME-17-0033
(C) 2017 Society for Endocrinology Printed in Great Britain
Published by Bioscientifica Ltd. 